\title{
Bowel dysfunction following spinal cord injury: a description of bowel function in a spinal cord-injured population and comparison with age and gender matched controls
}

\author{
AC Lynch ${ }^{1}, \mathrm{C} \mathrm{Wong}^{1}$, A Anthony ${ }^{2}, \mathrm{BR}_{\mathrm{Dobbs}}{ }^{1}$ and FA Frizelle*,1 \\ ${ }^{1}$ Department of Surgery, Christchurch Hospital, New Zealand; ${ }^{2}$ Spinal Injuries Unit, Burwood Hospital, Christchurch, \\ New Zealand
}

Study design: A controlled, descriptive and comparative, questionnaire based study.

Objectives: To describe the bowel function of spinal cord injured (SCI) patients and compare this with a general community control group.

Setting: Christchurch, New Zealand.

Methodology: A postal questionnaire was sent out to past SCI patients of the Burwood Spinal Injuries Unit, Christchurch, New Zealand, and age/gender matched with controls randomly selected from the electoral roll. Permission was obtained from SCI participants to retrieve data relating to their injury from hospital case notes. The questionnaire detailed general bowel function, influence of bowel problems on everyday life, incidence of incontinence and methods of defecation. A Faecal Incontinence Score was generated according to an established incontinence grading scheme.

Results: Questionnaires were sent out to 1200 SCI patients and 1200 control subjects. Of these, 467 completed questionnaires were returned from SCI patients and age/gender matched from the 668 returned control questionnaires. Mean Faecal Incontinence Score was higher for SCI patients than controls $(P<0.0001)$, and for complete compared with incomplete injury $(P=0.0023)$. Age or time from injury did not affect Faecal Incontinence Score. Incontinence affected quality of life for $62 \%$ of SCI patients, compared with $8 \%$ of controls. Faecal urgency and time spent at the toilet were also significantly higher for the SCI group (39\% of SCI patients use laxatives, compared with $4 \%$ of controls $(P<0.0001))$. Haemorrhoidectomy was more common $(P<0.001)$ in the SCI population $(9 \%$ vs $1.5 \%)$, particularly among those requiring manual evacuations.

Conclusion: SCI has a significant effect on bowel function in terms of faecal incontinence, urgency, and toileting methods. This results in a marked impact on quality of life. While bowel function may deteriorate with time, most patients with poor function can be identified early implying a role for early intervention in those with potential bowel problems, such as colostomy or ACE procedure.

Sponsorship: Dr AC Lynch had a Royal Australian College of Surgeons Foundation Research Scholarship and a grant for expenses was provided by The Burwood International Spinal Trust.

Spinal Cord (2000) 38, 717-723

Keywords: spinal cord injury; bowel function; faecal incontinence

\section{Introduction}

Bowel function is a major physical and psychological problem for SCI patients. Difficulties with bowel management have rated as high as problems associated with loss of mobility in previous questionnaires. ${ }^{1}$ Following spinal cord injury, changes in bowel motility, sphincter control, and gross motor dexterity interact to make bowel management a major life-

*Correspondence: FA Frizelle, Department of Surgery, Christchurch Hospital, Ricarton Avenue, Christchurch, New Zealand limiting problem. Previous surveys have shown that approximately one third of subjects rank colorectal problems as worse than both bladder and sexual dysfunction. ${ }^{2,3}$

Most patients achieve adequate bowel management strategies, but the issues of time, dependency, and the unpredictability of episodes of faecal incontinence remain. This questionnaire was devised to examine why bowel dysfunction is perceived as one of the major problems for SCI patients. An age and gender matched control group was included for comparison. 


\section{Method}

A multifield questionnaire was posted out to 1200 past patients of the Spinal Injuries Unit, Burwood Hospital, Christchurch, New Zealand. All those selected had a documented neurological abnormality on discharge. Permission was obtained from the participants to retrieve data from their hospital case notes relating to level, degree, and date of injury.

The questionnaire (Appendix 1) detailed bowel function, incidence of incontinence and methods of defecation. Quality of life impairment was assessed by direct question. The Cleveland Clinic continence score ${ }^{4}$ was used to assess faecal incontinence. This system looked at type of incontinence (solid, liquid or gas), the need to wear a pad and impact on lifestyle. Each factor was scored according to frequency: 0 for never, to 4 for always. This gave a combined score of 0 for complete continence and 20 for complete incontinence (Table 1).

A similar 20-question multifield questionnaire, detailing daily bowel habit but not methods of defecation, was posted to 1200 randomly selected individuals from the province of Canterbury, New Zealand. Questionnaire recipients were randomly selected from a computer generated electoral roll supplied by the Electoral Enrolment Centre, Wellington, New Zealand. Replies were age and gender matched with those SCI patients who returned questionnaires. The study design and questionnaire had the approval of the Canterbury Hospital's Regional Ethics Committee.

\section{Results}

Demographic data

Of the two mailings to $1200 \mathrm{SCI}$ patients 478 completed questionnaires were obtained. From this initial group, 11 patients were excluded due to previous surgical procedures that may influence answers to questions on continence. The demographic data of the remaining 467 is presented in Table 2. Patients were grouped according to the level and severity of their injury as recorded in their case notes. High injuries were defined as being above $\mathrm{T}_{5}$, the uppermost level of

Table 1 Continence grading scale used to general Faecal Incontinence Score ${ }^{4}$

\begin{tabular}{|c|c|c|c|c|c|}
\hline Type of incontinence & Never & $\begin{aligned} & \text { Rarely } \\
&<1 / \text { month }\end{aligned}$ & $\begin{array}{c}\text { Frequency of incontinence } \\
\text { Sometimes } \\
>1 / \text { month },<1 / \text { week }\end{array}$ & $\begin{array}{c}\text { Usually } \\
>1 / \text { week, }<1 / \text { day }\end{array}$ & $\begin{array}{l}\text { Always } \\
>1 / \text { day }\end{array}$ \\
\hline Solid & 0 & 1 & 2 & 3 & 4 \\
\hline Liquid & 0 & 1 & 2 & 3 & 4 \\
\hline Gas & 0 & 1 & 2 & 3 & 4 \\
\hline Wears pad & 0 & 1 & 2 & 3 & 4 \\
\hline Lifestyle alteration & 0 & 1 & 2 & 3 & 4 \\
\hline
\end{tabular}

Table 2 Demographic data for spinal cord injured (SCI) respondents $(n=467)$ and controls $(n=467)$

\begin{tabular}{|c|c|c|c|c|c|c|}
\hline & Male & Female & Total & $\begin{array}{l}\text { Mean age } \\
\text { (years) }\end{array}$ & $\begin{array}{l}\text { Mean time since } \\
\text { injury (years) }\end{array}$ & $\begin{array}{l}\text { Mean age at } \\
\text { injury (years) }\end{array}$ \\
\hline \multicolumn{7}{|l|}{ Complete injury } \\
\hline High & \multirow[t]{2}{*}{102} & \multirow[t]{2}{*}{11} & \multirow[t]{2}{*}{113} & 40 & \multirow{6}{*}{$\begin{array}{c}16 \\
1.5-32.1 \\
16 \\
1.8-42.1 \\
15 \\
1.3-38.1\end{array}$} & \multirow{6}{*}{$\begin{array}{c}25 \\
3.7-64.2 \\
29 \\
13.4-60.1 \\
28 \\
12.8-60.5\end{array}$} \\
\hline range & & & & $15-71$ & & \\
\hline Thoracic & \multirow[t]{2}{*}{83} & \multirow[t]{2}{*}{18} & \multirow[t]{2}{*}{101} & 44 & & \\
\hline range & & & & $20-67$ & & \\
\hline Lumbosacral & \multirow[t]{2}{*}{16} & \multirow[t]{2}{*}{5} & \multirow[t]{2}{*}{21} & 43 & & \\
\hline range & & & & $26-75$ & & \\
\hline \multicolumn{7}{|l|}{ Incomplete injury } \\
\hline High & \multirow[t]{2}{*}{97} & \multirow[t]{2}{*}{24} & \multirow[t]{2}{*}{121} & 46 & \multirow{6}{*}{$\begin{array}{c}13 \\
0.7-35.1 \\
16 \\
2.1-36.0 \\
11 \\
0.9-32.7\end{array}$} & \multirow{6}{*}{$\begin{array}{c}32 \\
6.9-81.6 \\
28 \\
6.9-55.9 \\
34 \\
9.0-61.7\end{array}$} \\
\hline range & & & & $15-89$ & & \\
\hline Thoracic & \multirow[t]{2}{*}{37} & \multirow[t]{2}{*}{8} & \multirow[t]{2}{*}{45} & 44 & & \\
\hline range & & & & $22-72$ & & \\
\hline Lumbosacral & \multirow[t]{2}{*}{49} & \multirow[t]{2}{*}{17} & \multirow[t]{2}{*}{66} & 45 & & \\
\hline range & & & & $22-67$ & & \\
\hline \multirow{2}{*}{$\begin{array}{l}\text { Total } \\
\text { range }\end{array}$} & \multirow[t]{2}{*}{384} & \multirow[t]{2}{*}{83} & \multirow[t]{2}{*}{467} & 43.5 & 14 & 29 \\
\hline & & & & $15-89$ & $0.7-42.1$ & $4-81.6$ \\
\hline \multirow{2}{*}{$\begin{array}{l}\text { Controls } \\
\text { range }\end{array}$} & \multirow[t]{2}{*}{384} & \multirow[t]{2}{*}{83} & \multirow[t]{2}{*}{467} & 45.3 & & \\
\hline & & & & $17-78$ & & \\
\hline Nonparametric Spearman & 0.60 & 0.823 & 0.636 & & & \\
\hline Correlation Coefficient & 3 & & & & & \\
\hline
\end{tabular}


the sympathetic chain. Thoracic injuries were defined as being from $T_{5}$ down to and including $T_{12}$. Lumbosacral lesions were below $T_{12}$. Degree of injury was classified from the most recent neurological assessment in the case notes as complete or incomplete. Age at injury and time since injury was also recorded. Controls were age and gender matched, their demographic data being presented in Table 2. Nonparametric Spearman Correlation Coefficients showed effective age pairing for each gender and the group as a whole $(P<0.0001)$.

\section{Faecal Incontinence Scores}

Faecal Incontinence Scores were higher for SCI patients compared to their controls for all levels and degree of injury $(P<0.0001$, two-tailed Mann-Whitney $U$-statistic), and also between complete and incomplete SCI $(P<0.0023)$ Figure 1. Faecal Incontinence Scores were lower for those SCI patients with high injuries compared to lower injuries $(P<0.01)$. No significant difference was demonstrated between mean scores for males and females within any group.

The Faecal Incontinence Score for SCI patients (Figure 2) did not change with age $(P=0.38$, twotailed Spearman rank correlation), or time since injury (Figure 3, $P=0.31$ ). Control subjects demonstrated a

Complete Injury

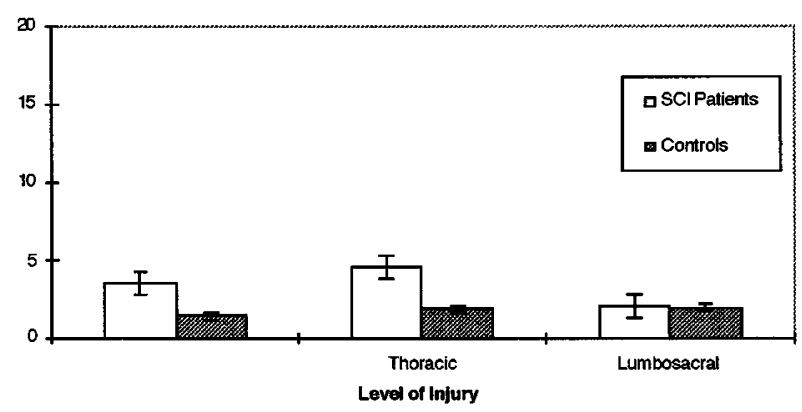

Incomplete Injury

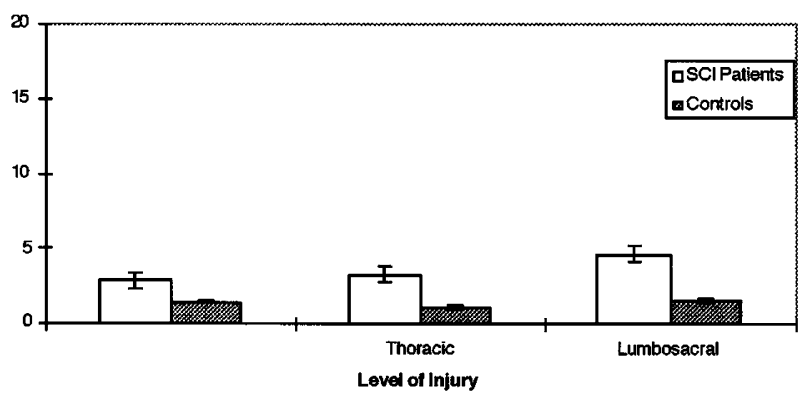

Figure 1 Mean Faecal Incontinence Score for SCI patients and age/gender matched controls according to level and degree of injury. This demonstrates a higher score for both level and degree of SCI injury for patients when compared to the control group $(P<0.0001)$. Scores are mean $\pm \mathrm{SE}$ deterioration in continence with increasing age $(P<0.0001)$ that was not reflected in SCI patients' scores.

\section{Bowel motion frequency}

Average weekly bowel motion frequency for SCI patients was $6.6 \mathrm{BM} /$ week (range from $4.7 \mathrm{BM} /$ week for complete cervical injuries to $12 \mathrm{BM} /$ week for incomplete lumbosacral injuries). This was less frequent than the control group, where average frequency was $9.3 \mathrm{BM} /$ week $(P<0.0001)$. SCI patients with complete injuries had less frequent bowel motions (5.5 BM/week) than those with incomplete injuries (7.7

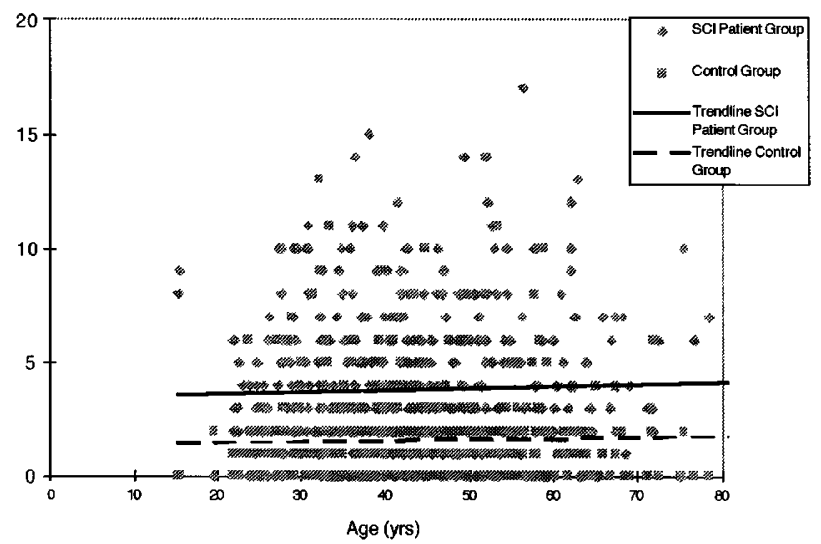

Figure 2 Graph of Faecal Incontinence Score $v s$ age for patients with spinal cord injuries and their age/gender matched controls $(n=467)$. Trendlines have been inserted for each group. There was a significant change in score with age for controls $(P<0.0001)$, but not for SCI patients $(P=0.38$, two-tailed Spearman rank correlation)

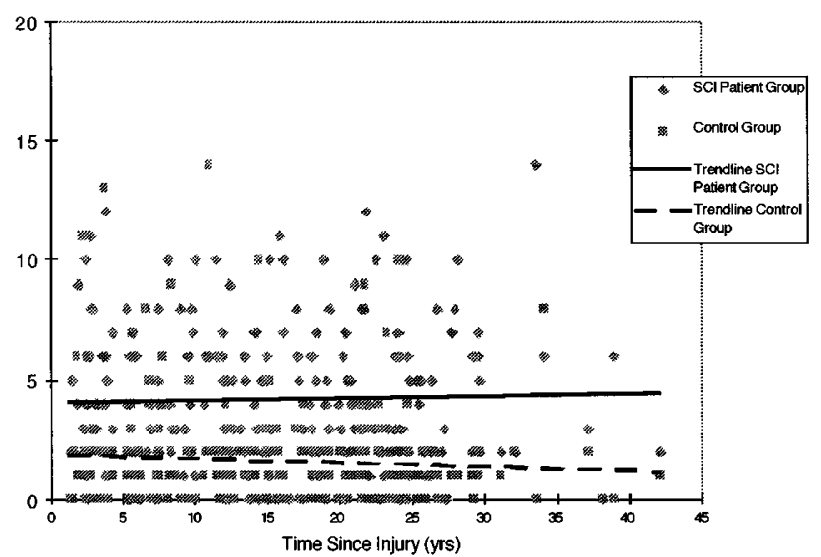

Figure 3 Graph of Faecal Incontinence Score $v s$ time since injury for patients with spinal cord injuries and their age/ gender matched controls $(n=467)$. Trendlines have been inserted for each group. There was no significant change in score with age for SCI patients $(P=0.31$, two-tailed Spearman rank correlation) 
$\mathrm{BM} /$ week, $P=0.0002)$. There was no change in bowel motion frequency with age or time since injury for patients or controls.

\section{Gas/solid discrimination}

The majority of controls $(85.4 \%)$ stated that they can always tell the difference between gas and liquid, compared with $43.5 \%$ of SCI patients. SCI patients with complete injuries were poor discriminators compared to incomplete injuries $(P=0.006$, Chisquared test for independence).

\section{Effect of incontinence on everyday activities}

A majority of controls were never affected by incontinence $(92.3 \%)$, compared with only $43.9 \%$ of SCI patients $(P<0.0001$, Fisher's exact test $)$. At the opposite end of the spectrum, $8.1 \%$ of SCI patients always have their everyday lives affected by incontinence, compared with $0.4 \%$ of controls. The effect of incontinence (either good or bad) on a persons life, either SCI or control, was reflected in similar scores in other components of the incontinence scale. SCI patients with complete injuries were more likely to have incontinence affect their lives $(11.5 \%$ always affected) than those with incomplete injuries $(4.7 \%$ always affected).

\section{Time at toilet}

The median time spent at the toilet each day was 15 to $30 \mathrm{~min}$ for SCI patients with complete injuries, and less than $15 \mathrm{~min}$ for those with incomplete injuries. Mean time for controls was less than 15 min per day. Only $9 \%$ of controls spent more than $15 \mathrm{~min}$ a day toileting, compared with $61 \%$ of SCI patients. Within the patient group, $13.3 \%$ of those with complete cervical injuries spent more than 60 min per day toileting, compared with less than $7 \%$ for all other groups of patients, and no controls.

SCI patients spent longer at the toilet with increasing time from injury $(P=0.0009)$. Those who spent less than 15 min per day sustained their injury an average of 13.1 years ago, compared to 16.5 years for those who spent longer than $60 \mathrm{~min}$. Age did not influence time spent at the toilet for either SCI patients or controls. The faecal incontinence score was higher for both SCI patients and controls who spend longer at the toilet.

\section{Assistance with toileting}

SCI patients with higher injuries, either complete $(P<0.0001) \quad$ or incomplete $(P=0.0002)$ required assistance more frequently than other SCI patients. Thus, $82.3 \%$ of those with complete high injuries required assistance, compared with $14.3 \%$ of those with complete lumbosacral lesions.

\section{Urgency}

Faecal urgency was assessed by asking respondents how long defecation could be delayed, whether $15 \mathrm{~min}$, a few minutes only, or not at all. Overall $81 \%$ of controls could delay defecation for more than a few minutes, compared with only $41 \%$ of SCI patients. The Faecal Incontinence Score was greater for SCI patients and controls who were unable to delay defecation $(P<0.001)$.

\section{Methods of evacuation}

Overall $43.2 \%$ of SCI patients and $23.2 \%$ of controls took extra fibre. There was no difference for level or degree of injury. For controls, increasing age resulted in more frequent fibre use (mean age of fibre users is 48.1 years, against no fibre users mean age of 44.3 years, $P=0.0002$ ). For SCI patients, average age for fibre users was 46.1 years, against 41.7 years for those who do not $(P=0.0005)$. There was no change in fibre use with time since injury $(P=0.10)$, or incontinence score $(P=0.10)$.

Laxatives were used occasionally or regularly by $39 \%$ of SCI patients, compared with $4 \%$ of controls $(P<0.0001$, Fisher's exact test $)$. Of note, $56 \%$ of those with complete cervical injuries are regular users of laxatives. For controls, there was no change in frequency of laxative use with either age $(P=0.36)$, or incontinence score $(P=0.31)$. For SCI patients, laxative use became more frequent with increasing time since injury $(P=0.005)$, but not with age $(P=0.95)$, or incontinence score $(P=0.10)$.

Enemata were used by $10.9 \%$ of the SCI patient population, with approximately twice as many patients with complete injuries compared to those with incomplete injuries $(P<0.0001$, Fisher's exact test $)$. No controls used enemata.

Regular manual evacuation was more frequent among those SCI patients with complete injuries $(67 \%)$ compared to those with incomplete injuries $(25.4 \%)(P<0.0001$, Fisher's exact test). $62.7 \%$ of SCI patients used digital stimulation to effect defecation. Seventy-one $(15 \%)$ patients used suppositories, mainly those with higher injuries. Other strategies for aiding defecation mentioned by patients included: hot drinks and beer, coughing, exercise, massage, pushing, rubbing arms, tapping, and yoga.

\section{Surgery}

Fifty patients reported previous surgical procedures including surgery for: haemorrhoidectomy or mucosal prolapse (43), colostomy formation (six), rectal prolapse (three), Brindley stimulator implantation (three), ileal conduit formation (two), sigmoid volvulus (one), Mitrofanoff valve formation (one), perforated duodenal ulcer (one), anorectal anomaly (one), and adhesions (one).

Haemorrhoidectomy was more common in the SCI population $(P<0.001$, Fisher's exact test), as the 
procedure was reported in only seven out of $467(1 \%)$ controls. Mean incontinence score for patients with haemorrhoidectomy was 4.4 and 3.7 without, and for controls, 2.1 with and 1.5 without. Time since injury was greater for those patients who had had an haemorrhoidectomy $(P<0.0001)$, at 20.1 years compared to those who had not at 13.6 years. There was no difference with age in SCI patients, mean age 43.8 years, or for controls, mean age 45.1 years. Patients who sometimes or regularly required manual evacuations were more likely to have had haemorrhoidectomy than those who never did $(P=0.02)$.

\section{Discussion}

Bowel function is a major problem for SCI patients. Patients have rated difficulties with bowel management as being similar to problems associated with loss of mobility and sexual function. ${ }^{1}$ Few other studies have collected information on the characteristics of bowel function in chronic SCI patients, and none have made direct age and gender matched comparisons with control groups. ${ }^{1}$ A postal questionnaire was felt to be the most practical method of contacting SCI patients who are widely distributed across the country. Comparative studies have demonstrated a concordance rate of approximately $86 \%$ between a bowel history assessed by questionnaire and a scrupulouslykept diary. ${ }^{5}$

Approximately one third of SCI patient questionnaires were returned. Some patients had not been contacted by the Burwood Spinal Injuries Unit for some years. Of those not returned, it is unknown how many were undelivered due to an incorrect address, or how many people declined to participate. Although the Spinal Injuries Unit attempts to maintain contact with its patients, referrals are from the lower twothirds of New Zealand and past patients are spread throughout the country following discharge. Those that responded may have been motivated to do so because of their own bowel-related problems. The low response from 1200 questionnaires of only 478 in the SCI patient group and the likewise substantial drop in controls may have lead to bias and skewed both groups towards those with abnormal bowel function.

\section{Bowel problems}

Chronic gastrointestinal problems are common in the SCI population. ${ }^{1}$ The results presented here show that the incidence of faecal incontinence in SCI patients is more common than the general population and comparable to that seen in other surveys. ${ }^{2}$ The presentation and degree may also be greater. Even for those people with infrequent episodes of incontinence, its unpredictability is a handicap, especially if hand dexterity and mobility are limited. The decreased ability to discriminate gas and liquid for complete SCI patients also make the chance of faecal incontinence more likely. This is supported by noting that the average Faecal Incontinence Score is higher for those patients who are never able to discriminate gas and liquid (5.3), compared to those who always can (2.3).

It is apparent that even with medications and other methods SCI patients do not achieve a bowel motion frequency similar to the control population. Previous studies have found that over half of all SCI patients with an injury above L2 will suffer from constipation. ${ }^{2}$ A similar pattern was found here with higher injuries defecating less frequently compared to lower injuries and controls. Changes to the extrinsic autonomic innervation to the bowel can decrease the normal postprandial increase in motility and decrease colonic compliance. However, diarrhoea produced by laxatives and the resultant risk of incontinence may explain why only about one third of SCI patients use them regularly.

This questionnaire does not demonstrate a change in Faecal Incontinence Score with either duration of injury or age for SCI patients. One survey of bowel dysfunction in SCI patients found that chronic gastrointestinal problems were rare in the first 5 years following injury, but problems with defecation became more common with increasing time. The incidence of abdominal pain and distension was increased in longterm SCI patients (more than 18 years since injury) whose bowel regimen was less frequent that once a day. ${ }^{6}$ Two observations from our data may indicate constipation becoming more of a problem with increasing time from injury. The increase in laxative use by SCI patients was not related to a concomitant increase in bowel motion frequency. Also, the increase in Faecal Incontinence Score for control subjects with age (Figure 2) was not matched by the SCI patient population. Another study, looking at chronic gastrointestinal problems in SCI patients concluded that bowel habit appeared to settle by about 6 months after injury, and that subsequent bowel dysfunction was not related to age, duration or level of injury. ${ }^{6}$

If the severity of bowel related problems is not related to duration of injury, then this suggests that those who are having difficulties with bowel dysfunction will continue to have problems. These may potentially be treatable with simple preventative measures, ${ }^{6}$ or appropriate management can be instituted at an early stage.

\section{Impact on lifestyle}

Disordered bowel function has a major impact on lifestyle. Hanson et al reported that $80 \%$ of male paraplegics and $46 \%$ of male tetraplegics would rank bladder and bowel as their greatest functional loss after loss of mobility. Interestingly, when they asked the same question of spinal unit staff, only 39\% ranked their patients bladder and bowel problems as highly. Completeness of injury seems to have a greater effect on bowel problems affecting lifestyle than level of injury, perhaps due to the greater difficulty associated with toileting and the need for assistance. ${ }^{6}$ The ability 
to delay defecation is an important component of everyday life. Sixty per cent of SCI patients, compared to $17 \%$ of controls can delay defecation a few minutes only. This is a major problem when mobility is limited and a wheelchair-able toilet may not be nearby.

\section{Toileting}

SCI patients spent longer at the toilet than controls $(P<0.0001)$, especially those doing manual evacuations. $^{9}$ The need for assistance with toileting relates to the level of injury and has implications for provision of carers and dependence on family members. It is recognised that having family members perform such intimate tasks can be emotionally charged and negatively affect family interrelationships. ${ }^{10}$

\section{Bowel management}

More SCI patients require bowel related medication on a regular basis than the age and gender matched control group. While laxatives can improve colonic motility, looser and more frequent bowel motions may result in an increased incidence of faecal incontinence. Regular fibre and adequate fluid intake is recommended because of bulking and stool softening properties. Keeping the stool soft facilitates transit and prevents impaction. However, the effects of increased fibre on colonic function after SCI are not yet fully understood, and may be counterproductive. Significantly increasing dietary fibre in a group of SCI patients with a range of injuries resulted in an increase in mean colonic transit time from $28.2 \mathrm{~h}$ to $42.2 \mathrm{~h}$ $(P<0.05)$, and rectosigmoid transit time from $7.9 \mathrm{~h}$ to 23.3 h $(P<0.02) .{ }^{11}$

As might be expected, digital stimulation and manual evacuation are the commonest methods of defecation for patients with high complete SCI. Those with high injuries use digital stimulation to provoke reflex defecation, those with lower injuries are more likely to require manual evacuation. Haemorrhoids appear to be more common following SCI, especially in those requiring manual evacuation. They can become a frequent source of bleeding or autonomic dysreflexia. The occurrence of haemorrhoids, or more probably mucosal prolapse, may be multifactorial due to altered anorectal tone or trauma with manual evacuation.

\section{References}

1 Glickman S, Kamm MA. Bowel dysfunction in spinal-cordinjury patients. Lancet 1996; 347: $1651-1653$.

2 Levi R, Hultling C, Nash MS, Seiger A. The Stockholm spinal cord injury study: 1: Medical problems in a regional SCI population. Paraplegia 1995; 33: $308-315$.

3 DeLooze $\mathrm{D}$ et al. Constipation and other chronic gastrointestinal problems in spinal cord injury patients. Spinal Cord 1998; 36: $63-66$.
4 Kuijpers HC. Fecal Incontinence. In: Wexner SD Vernava AM (eds). Clinical Decision Making in Colorectal Surgery. IgakuShoin: New York, 1995, Ch. 19.

5 Manning AP, Wyman JB, Heaton KW. How trustworthy are bowel histories? Comparison of recalled and recorded information. $\mathrm{Br}$ Med J 1976; 2: $213-214$.

6 Stone JM, Nino-Murcia M, Wolfe VA, Perkash I. Chronic gastrointestinal problems in spinal cord injury patients: A prospective analysis. Am J Gastroenterol 1990; 85: 1114-1119.

7 Han TR, Kim JH, Kwon BS. Chronic gastrointestinal problems and bowel dysfunction in patients with spinal cord injury. Spinal Cord 1998; 36: $485-490$.

8 Hanson RW, Franklin MR. Sexual loss in relation to other functional losses for spinal cord injured males. Arch Phys Med Rehabil 1976; 57: 291 - 293.

9 Gulati MS, Kirshblum SC, Vorman S, O'Connor KC. Bowel care practices in chronic spinal cord injury patients. Arch Phys Med Rehabil 1995; 76: 1040.

10 Steins SA, Bergman SB, Goetz LL. Neurogenic bowel dysfunction after spinal cord injury: Clinical evaluation and rehabilitative management. Arch Phys Med Rehabil 1997; 78: S86-S102.

11 Cameron KJ, Nyulasi IB, Collier GR, Brown DJ. Assessment of the effect of increased dietary fibre intake on bowel function in patients with spinal cord injury. Spinal Cord 1996; 34: 277-283.

\section{Appendix 1. Questionnaire sent to spinal cord injured patients}

Please circle beside your answer to the questions below.

I. Do you consider your bowel pattern normal?

1. Yes

2. No

II. How many bowel motions do you have?

1. On average over 24 hours?

III. or, On average over a week?

IV. What best describes your day-time bowel control (continence)?

1. Perfect control (continence)

2. Leakage of gas (wind) at times

3. Leakage of mucus or liquid motion occasionally

4. Leakage of mucus or liquid motion frequently

5. Leakage of solid motions occasionally

6. Leakage of solid motions frequently

V. What best describes your night time bowel control (continence)?

1. Perfect control (continence)

2. Leakage of mucus or liquid motion occasionally

3. Leakage of mucus or liquid motion frequently

4. Leakage of solid motions occasionally

5. Leakage of solid motions frequently

VI. Do you have to wear a Pad?

1. Never at any time

2. Sometimes

3. Day times only

4. Night times only

5. Day and night 
VII. Can you tell the difference between gas (wind) and liquid or solid motion?

1. Never

2. Occasionally

3. Sometimes

4. Often

5. Always

VIII. If you are incontinent, does it affect your everyday activities?

1. Never

2. Occasionally

3. Sometimes

4. Often

5. Always

IX. When you feel the need to have a bowel motion, how long can you wait before going?

1. Need to go immediately

2. Can hold on for a few minutes only

3. Can hold on at least 15 minutes

X. How often do you need to have a bowel motion within one hour of a previous motion?

1. Never

2. Occasionally

3. Sometimes

4. Often

5. Always

XI. Are your stools or bowel motions usually:

1. Loose or watery

2. Soft and firm

3. Hard

XII. How much time do you spend at the toilet for your bowels each day?

1. Less than 15 minutes

2. 15 to 30 mins

3. 30 mins to 1 hour

4. More than 1 hour

XIII. Do you need assistance with toileting?

1. Yes

2. No
XIV. Do you take a laxative?

1. Yes

2. No

If so, how often do you take it?

3. Sometimes, as needed

4. Regularly

XV. Do you take extra fibre in your diet?
1. Yes

2. No

XVI. Do you require regular enemas or irrigations for your bowel?
1. Yes

2. No

XVII. Do you take a constipating agent to slow down' your bowel?

1. Yes

2. No

XVIII. Do you use your finger to stimulate bowel motions?

1. Yes

2. No

XIX. Do you need to empty your bowel manually?

1. Yes

2. No

If so, how often?

3. Sometimes

4. Regularly

XX. Do you use any other methods to initiate bowel motions?

1. Yes

2. No

If so, please specify the method(s):

XXI. Have you had previous bowel surgery?

1. Yes

2. No

If so, please specify what operation: 